\title{
Coming to Terms with Engineering Design as Content
}

\begin{abstract}
Theodore Lewis
With the publication of standards for teaching, learning, and the inculcation of technological literacy (International Technology Education Association, 2000), technology education in the United States has made a significant leap forward toward greater acceptance as a valid school subject. Standards represent content terrain claimed by a community of practitioners, and once stakes are put down, it is left to adherents to move in seeking title. It is doubtful whether we will witness a rush towards bio-technology or medical technology, new areas in the standards that do not naturally issue from our accustomed traditions. But for design there will be great interest since this is a content area over which the field has long toiled. Design is arguably the single most important content category set forth in the standards, because it is a concept that situates the subject more completely within the domain of engineering. Four of the 20 standards address the question of design directly. Standard 8 deals with the "attributes of design;" Standard 9 with "engineering design;" Standard 10 with "trouble shooting, research and development, invention and innovation, and experiment in problem solving; and Standard 11 with the "design process."

It is not inconsequential that the foreword heralding the standards is authored by William Wulf, in his capacity as President of the National Academy of Engineering. This is a significant benediction for a subject whose advocates have for the past decade or so been of the view that its acceptance by the public and by the dominant academic culture of schools turned on the degree of rapprochement that could be worked out with the science as well as the engineering communities. The Project 2061 curriculum standards acknowledged the common epistemological ground shared by science and technology as school subjects, embodied in the designed world (American Association for the Advancement of Science, 1993; Johnson, 1989). With ties with science thus formalized, engineering was but a step away. The sentiments expressed by Bensen \& Bensen (1993) foreshadowed what appears now to be a significant opportunity for the field of technology education to lay claim to aspects of engineering as part of its curriculum purview. Arguing that the subject should
\end{abstract}

Theodore Lewis (Lewis007@umn.edu) is Professor in the Department of Work Community and Family Education at the University of Minnesota, St. Paul. 
assume the name "Engineering and Technology," they wrote: "it is imperative that we engage the engineering profession, the companies that employ them, the universities that educate them, and the associations and accreditation bodies that set the standards and benchmarks for them, to become involved in bringing the curriculum into the twenty-first century" (p.5). These sentiments are now shared by important professional engineering bodies, such as the Institute of Electrical and Electronics Engineers (IEEE), as can be seen in the strategies set forth by this body at its "Technological Literacy Counts" conference. The prevailing sentiment was that cementing ties between the subject and the field of engineering had become a high priority, such ties to include joint curricular endeavors (Institute of Electrical and Electronics Engineers, 1998). Writing from the vantage point of the National Academy of Engineering, Pearson \& Young (2002) emphasized the need to make engineering accessible to all citizens through the inclusion of engineering design in the curriculum.

The climate for engagement with engineering is now inviting; technology education is being viewed favorably as a credible means of advancing the goal of technological literacy for all, and a means by which students can gain insights about and interest in engineering careers.

This article addresses the challenges posed by engineering design as a content area of technology education. What adjustments will technology teachers have to make in their approach to teaching and learning when they teach design as engineering in response to the new standards? How faithful to engineering as practiced must their approach be? There is already some advocacy in the literature that greater attention will need to be paid to mathematics and science, where these subjects underpin design. Cotton (2002) proposed that mathematical theories should be applied to design in technology education classrooms, and that students should be encouraged to use mathematics to predict the outcomes of their designs. Neumann (2003) suggested that students should spend more time engaged in research and redesign activities, as is the case in British schools. Roman (2001) encouraged an integrative approach to design that incorporates mathematics and applied science, in keeping with the cross-cutting nature of engineering. Afoot here is a discourse on curriculum integration that raises challenging questions for the field, including whether technology teachers as normatively trained are equipped to venture into the teaching of engineering design.

Westberry (2003) has laid groundwork for the issues that are to be taken up here, by calling attention to alternative models of design, and exploring the challenges inherent in teaching it across the grade levels. This article necessarily pays attention to approaches to design, but it especially also examines design pedagogy within engineering education. How is design taught to engineers? What logics underpin such teaching? The structure is as follows: (a) the design/problem solving literature of technology education is reflected upon, (b) the question "what is engineering design?" is explored, (c) approaches to the teaching of design in engineering education are examined, (d) reflections on 
engineering design follow, and finally (e) conclusions and implications inherent in coming to terms with engineering within technology education are set forth.

\section{Design and Problem Solving in Technology Education}

Design has been a focus in the practice and literature of technology education, often embedded within discourse on problem solving. Its prominence has increased with the shift in American curricular thinking about the subject from a disciplinary to a process focus (e.g. Savage \& Sterry, 1990). De Luca (1991) provided a survey of problem solving approaches employed in technology education classes, surmising that design activities teach students how to think, once the learning environment created by the teacher is conducive to creative behavior. Johnson (1988) examined the problem solving literature of technology education and proposed a model for research comprised of three components, the solver, the solving process, and the problem. He suggested that the model could be used to investigate problems relating to trouble shooting or designing. Employing the model empirically he found differences between expert and novice problem solvers (Johnson, 1989; Johnson \& Chung, 1999). In one study, the primary performance difference between novices and expert trouble shooters was found to be the quality of information acquired and the quality of the hypotheses they generated in solving problems (Johnson, 1989). In a subsequent study, Johnson \& Chung (1999) used think-aloud problem solving methodology to compare the cognitive performance of an experimental group over a comparison group. The approach helped learners evaluate trouble shooting hypotheses, and potential faults in a system.

One dimension of the design/problem-solving literature has focused upon the critical question of the professional development of teachers. Zubrowski (2002) examined the integration of engineering and science via a three-phase pedagogical model comprised of (1) exploration during which students mess about preliminarily, (2) introduction of a standard model, and (3) improvement of the preliminary model. This pedagogical model was used as the backdrop for designing engineering projects. He found that the approach fostered the teaching of science as well as interdisciplinary collaboration among teachers. Koch \& Burghardt (2002) described teachers' involvement in action research, as they developed design challenges for their students. Here too, design was said to have fostered curriculum integration.

Another focus of the design/problem solving literature has been upon learning in the elementary grades. Denton (1994) examined reactions of children to design and technology simulation activities aimed at teaching them about industry and economics. The motivation of students improved as they made connections between simulations and regular design work. Foster \& Wright (2001) found that children increased their technological capability and technological knowledge, having participated in design and technology activities. Gustafson, Rowell \& Guilbert (2000) examined children's awareness of structures, finding that they can work out regimes for testing and evaluating the strength of a structure represented on paper. 
Addressing an area of need in the teaching of design and problem solving, Custer, Valesey, \& Burke (2001) validated an instrument for assessing student learning. The work was premised on the view that problem solving can be reduced to a set of discrete, observable behaviors that can be captured via appropriate rubrics. Assessment in technology education is still an undeveloped aspect of the subject, and when associated with the teaching of design it will pose its own peculiar challenges. Just what are students expected to learn when they are taught design, and how is their knowledge to be ascertained? How does the context of engineering alter the way in which we might approach the assessment of design?

Orienting the conversation on design toward creativity, Lewis, Petrina, \& Hill (1997) suggested that problem finding has been a missing dimension of the design/problem-solving literature, contending that it is just as important in technology education classes to have children pose problems as it is to have them solve them. The centrality of problem finding (or problem posing) in design/problem solving can be seen in seminal contributions to the creativity literature, notably Getzels, 1982; and Getzels \& Csikszenthmihalyi, 1976; and Wertheimer, 1968. In his Productive Thinking, Wertheimer (1968) set forth that "the function of thinking is not just solving an actual problem, but discovering, envisaging, going into deeper questions." Mumford, Reiter-Palmon, \& Redmond (1994) contend that problem posing contributes to creative problem solving, and that it is inherently a cognitive activity. The new engineering thrust of technology education will require that problem posing be given at least as high a priority as problem solving. Children will have to be taught to imagine to think like engineers, making observations in the world around them, and finding areas of need for which technological design would be central to the solution.

\section{What is Engineering Design?}

Since design stands at the core of both craft and engineering traditions, its meaning and usage in technology education is not always settled. Where craft design draws on aesthetics primarily, engineering design has both creative as well as rational dimensions (e.g. Cross, 2000). It is necessary that the conception of engineering design that becomes normative as technology education teachers interpret the standards be an authentic depiction of design as it is conceived and practiced by engineers. This section of the article is in this vein.

Nature of engineering design

While engineering design is an agreed upon cognitive activity, there are nuances in how it is conceptualized. One dominant view is that design is the essence of engineering, an aspect of human ingenuity upon which the competitiveness of countries depend (Koen, 1994). Koen (1985, p. 50) has written further that engineers work "at the margin of solvable problems," proceeding from the known to the unknown. They work under conditions of 
change, uncertainty, and resource constraints. Koen explains that unlike scientists who proceed within the framework of scientific laws, engineers employ heuristic laws to arrive at design solutions. Heuristics do not guarantee solutions, but they reduce the search time in solving a problem.

Koen devised a taxonomy of heuristics that can be employed in engineering design, comprised of the following elements: (a) simple rules of thumb (e.g. one gram of uranium yields one megawatt of energy); (b) factors of safety (not trusting pristine calculations and adding a compensatory factor-such as to the calculated wall thickness of a pressure vessel); (c) attitude heuristics (such as the maxim that the engineer should always be ready to give a back-of-theenvelope answer to peculiar engineering questions); (d) risk heuristics (e.g. approaching new problems by making only small changes in what has worked; and (e) resource allocation heuristics (including allocating sufficient resources to the weak link in the design).

Pahl and Beitz (1996) write that the main task of engineers is to "apply their scientific and engineering knowledge to the solution of technical problems, and then optimize those solutions within the requirements and constraints set by the material, technological, economic, legal, environmental and human-related considerations" (p. 1).

Beyond the technical, design can also be situated in the realm of the psychological. It is creative, requiring grounding in mathematics and science, as well as in domain specific knowledge and experience. Design has systemic aspects, requiring optimization of given objectives within partly conflicting constraints. These authors identify types of designs, goals, and methods. Types include (a) novelty...new tasks and problems needing original design, which must proceed through all phases (b) adaptive...established solution principles held constant but the embodiment is adapted to changed requirements; (c) variant...sizes and arrangements of parts are varied within the original design parameters ("design within fixed principle"). Goals include (a) optimization of function, (b) minimization of cost, (c) aesthetic considerations, (d) ergonomic considerations, (e) and minimization of weight. Solution methods include (a) conventional (e.g. literature search), (b) intuitive, inclusive of preconscious or subconscious ideas or insight or flash, brainstorming, or using analogy, and (c) discursive... use of design catalogs or systematic combinations.

Reflecting upon everyday commonplaces (such as the aluminum soda can), Petroski (1996) emphasizes the importance of failure considerations in engineering design. He writes that 'What distinguishes the engineer from the technician is largely the ability to formulate and carry out the detailed calculations of forces and deflections, concentrations and flows, voltages and currents, that are required to test a proposed design on paper with regard to failure criteria." p.89. If designing a bridge, the engineer must calculate the load that individual structural members can safely carry before they buckle or come apart, and how much deflection can be allowed at the center of the bridge. Engineers can test a design on the drawing board or computer. Where failure conditions are indicated, the design is modified. Petroski writes that obviating 
failure is a design principle. Failure considerations extend beyond the technical to the environmental or aesthetic.

\section{Reflection}

As can be seen above, engineering design is viewed as a creative endeavor that proceeds in an environment of uncertainty, from known condition to unknown. Design solutions are framed by constraints, such as cost and safety. Though engineers are constrained by nature, and must rely upon mathematics and scientific principles, they differ from scientists in the extent to which they draw upon heuristics rather than scientific laws in making design decisions.

\section{Design processes}

Engineers rely on a variety of strategies when they design. Cross (2000) noted that these strategies continue to evolve. He pointed to a trend toward the formalizing of the design process. According to Cross, the new approaches can be classified into two broad groupings, namely creative methods and rational methods. Included in creative methods are brainstorming, synectics (such as analogical thinking and bisociation (see Koestler, 1969), and enlarging the problem space through dialectics - pitting an idea against its opposite. Rational methods involve breaking a problem into sub-problems, then arriving at subsolutions. He identifies a general process comprised of seven fundamental design stages, inclusive of clarifying objectives, establishing functions, setting requirements, determining characteristics, generating alternatives, evaluating alternatives, and improving details (p59). Cross makes clear that rational processes and creative processes are complementary, both aiming to improve the quality of design decision-making. Rational approaches to design do not preclude creativity.

The design process is not linear. Hinrichs (1992) pointed out that constraints may change in the course of the design, requiring the engineer to switch problem space, thereby making new solutions possible. Components of the design may change as well as the structure. Design is not a discrete engineering phase, Hinrichs points out, rather, that it is continuous through significant portions of the lives of projects. Middendorf \& Engelmann (1998) concur noting that engineering design is an iterative process requiring numerous decisions. They argue against an omnibus design method, contending that "By the very nature of design, the process used will be different, depending on the type of system or device to be designed, the state of the art, the supporting personnel and equipment available, the number of units likely to be made, and so on" p.8. Still, they set forth the outlines of a general approach comprised of the following:

1. problem definition, inclusive of recognizing a need, and the state of the art.

2. problem evaluation...need analysis, specifications, feasibility

3. synthesis...study of patents, development of alternate design concepts, determination of the most creative step 
4. analysis...mathematical models, computer simulations, test of physical models, optimization of design

5. communicate and manufacture p.11

They write that in the process of design if little scientific information is available then an intuitive approach might be needed. Where such information is available, as in the sizing of boilers, well defined mathematical procedures will be available. Similar general approaches to engineering design have been set forth (e.g. Cather, Morris, Philip \& Rose, 2001; Dominick, Demel, Lawbaugh, Frueler, Kinzel \& Fromm, 2001).

French (1992) set forth aids to design, beginning with the use of rough sketches and simple calculations to develop insight into unfamiliar problems. He suggested that the approach to solution ought to be diversified. The designer should proceed stepwise, remembering that ideas do not always arrive in their final form. Initial failures should not be rejected. French recommended seizing the essence of problems by increasing the level of abstraction during solution. One design solution approach he recommended is the use of combinative methods in which design functions are listed and matrixed against all possible solutions by which each can be done, the final product being a morphological chart that offers design options. The best combination of solutions is then determined (p.12). In a later work, French (1999) set forth a design schema that parallels a more generalized process approach as set forth by Cather et al, 2001; Dominick et al, 2001; and Middendorf \& Engelmann, 1998. The process begins with a need. The client is then questioned and the designer thereby arrives at a clear statement of problem. The problem statement generates broad solutions. The conceptual design stage follows, the approach being open ended, searching for schemes to solve the problem. There are tradeoffs between conflicting goals, with the focus being more on function than on form. French contends that this is the phase of the most striking improvements, where engineering science, practical knowledge, production methods and commercial considerations come together. At this stage the designer cannot predict how subsystems might react, or what options may have to be ruled out because of local conditions. Possible concepts or design schemes are then fleshed out such as selecting and sizing major subsystems. Rules of thumb are employed, followed by detailing and refining.

Dym (1994a) contends that the key element in engineering design is representation. A design problem may require a multiplicity of representations, such as those needing analytic physics-based models, geometric or visual analysis, economic or quantitative models, or verbal statements not easily captured by algorithms. Such requirements could be statements of function or intent. He agrees that the design process is evolutionary in nature, with choices to be made and alternative paths to follow as it unfolds. The process may include (1) clarifying the requirements of the client, (2) identifying the environment, (3) modeling the behavior (can the device be assembled?), (4) identifying the constraints (manufacturing, marketing, economic), (5) testing and evaluating the proposed design, (6) examination of whether there is a more 
economic or efficient design, and (7) documenting the completed design for the client (p.22).

Hubka (1982) identified similar general steps as French (1999) and as set forth in Dym (1994a), but he writes that the process of engineering design also includes a set of "strategic maneuvers." They include (a) iteration, strategies used when a direct solution is not possible and assumptions must be made in order to proceed onward to a solution; (b) abstraction, ignoring unimportant steps and concentrating on important ones; (c) concretization, moving from rough preliminary solutions to fine tuned ones; (d) improvement, starting from a feasible solution, using criticism to improve it (p.34). Mullins, Atman \& Shuman (1999) included an analysis phase comprised of the creation of mathematical and scientific models to study each alternative.

Cross (2002) provided insight into design by looking at the processes employed by three experts: designers respectively of racing cars, sewing machines, and bicycle luggage carriers. He found that though they functioned in different domains, these designers shared common general approaches to their work. All three adopted a systems approach to design, rather than a more restrictive approach. All relied upon first principles in their work. For example, the luggage designer focused upon triangulation to achieve rigidity and stiffness, while the racing car designer focused upon the physical forces that acted on a car. Finally, all three explored the problem space from particular perspectives that were dictated by the nature of the design situation and personal motivations, including the desire to provide pleasure to the product user. Cross found that the designers' behaviors could be explained by the concept of the reflective practitioner. He further pointed out that while each operated on a set of common approaches, it was not possible for them to switch between domains, since domain-based expertise required extensive training.

\section{Reflection.}

This brief examination of engineering design, its nature and processes, allows tentative comparison and contrast with design as traditionally conceived within technology education. One area of commonality seems to be that there is rough agreement on a general design procedure, inclusive of problem clarification, generation of possible solutions, evaluation of solutions, deciding on a solution, and representation and detailing of it. Beyond areas of commonality is a clear zone of divergence, beginning with assumptions about the knowledge base required by the design engineer. It is evident that engineering designers must posses a combination of scientific, mathematical, and domain-specific knowledge. In addition they must possess engineering design content knowledge, consisting of prior experience, knowledge of heuristics, ability to work within tight constraints, ability to make trade-offs, ability to change design in the course of a project, ability to design for manufacturability, and ability to conform to the demands of the customer. Engineering designers must sort through conflicting goals as they seek to 
optimize function. The starting point of design may vary and may include redesign

\section{Design in Engineering Education.}

Despite general agreement in the literature that design lies at the core of engineering, how it should be approached in the engineering curriculum at the university level is still unsettled. Dym (1994b) observed that design is still an area of contention, with some in the engineering community believing it lacks definitive content and rigor, while others contend that creativity cannot be taught. In a special issue of Engineering Education devoted to the teaching of design, authors examined the tensions. McMasters \& Ford (1990) expressed the view that schools of engineering should understand that engineering and design are synonymous. Noting that conceptions of design were not stable, they wrote of difficulties surrounding its inclusion in the college engineering curriculum. West, Flowers \& Gilmore (1990) lamented that design and build projects get low priority in the curriculum, with the tensions centered on the questionable value of hands-on learning.

Peterson (1990) wrote that unlike engineering science, "Design... is not a science and has no rigorous rules for progression. Both as taught and as practiced, it is almost invariably interdisciplinary. Design projects typically specify only desired performance, leaving task definition and solution synthesis to the student." p. 531. He cautioned that under prevailing pedagogic conditions, too little attention is paid to "creative questioning" p. 530.

In the years since this special issue, design in the engineering curriculum has become an area of heightened focus. The ensuing literature provides glimpses into how engineering schools seek to provide their students with design competence. The approaches vary; in some programs design is offered as a capstone course and in others as a freshman course.

Harris \& Jacobs (1995) described a capstone-project approach to design teaching. The method they adopt includes five phases, namely, conceptual design, analytic design, detailed design, construction and testing, and competition. These authors distinguished between problem solving and design. They add that whereas typical engineering problem solving provides all necessary information to solve a given problem, real design problems are open ended.

Wild \& Bradley (1998) proposed an engineering program featuring a concurrent approach to design. Concurrent design moves design away from a linear approach to problem solving. The basic design process is supported by theories including (a) Design for Assembly (DFA), which provides production information at the stage where alternative conceptual designs are being considered; (b) Design for Manufacture which is part of the detailed analysis of the best conceptual design; (c) Quality function development, which adds customer information to the process; (d)Failure Modes and Effects Analysis (FMEA), which enhances product reliability by heading off failure at early stages of design, (e)Taugushi Method Analysis, which quantifies cost at 
production and at consumption point; and (f)Rapid prototyping, which is used to connect the design to the prototype. These authors divide the process of design into conceptual and analytic phases.

Mullins, Atman \& Shuman (1999) found that one semester of engineering design led to improvement in the sophistication with which students approached the design process, but not in the quality of their solutions. They used techniques such as verbal protocols to document and measure students' engagement in the design process. Petroski (1998) described an approach to teaching a freshman engineering design course in which students were required to improve the Gem paper clip. He writes that while conventional wisdom says that first-year students do not have the requisite analytic tools gained through engineering design courses, it is possible to challenge them meaningfully through his approach. The course required no prerequisite, yet provided a multidimensional experience and challenge, including exposure to the patent system. The gem paper clip has faults of function and form, allowing students to see "the nature of design, which is how to solve a problem of function while not introducing more new problems, i.e., by keeping undesirable consequences to a minimum" p.445. Petroski wrote that design always entails compromises and tradeoffs, thus:

What students learn through the exposure to a score or more of paper clip patents ... is that while patents may fairly present a new design as an improvement over the prior art, with each new design also come compromises. To make a paper clip that grips better, one risks having one that that also tends to rip papers more aggressively upon removal. To make a paper clip that has a greater capacity than a standard Gem, more wire must be used and so the clip must be more bulky and more expensive to manufacture. (p. 446).

Pace (1999) described a structured approach to teaching mechanical design principles in an engineering foundations course at a British university. The course adopts a product analysis approach. Students are presented with an artifact that must meet the following basic criteria: (1) be the embodiment of mechanical principles, (2) perform a simple-to-understand, interesting function, (3) be available in alternative designs for comparison, and (4) be testable for functional performance using desk-top apparatus. An interesting aspect of Pace's account is the importance he attaches to the fact that English students are exposed to Design and Making (or technology education) in the school curriculum ahead of their attending university and seeking a degree in engineering. Students are aided by having taken this subject in their high school years.

Koen (1994) examined the teaching of design, concluding that the behaviors of practicing engineers are not necessarily the same as those of engineering students. He hypothesized that design is really a set of behaviors. Experts can give a quick answer if that is needed, based on experience. Thus, "To teach engineering design is to develop a strategy for changing the repertoire of design behaviors of the student to that of an acceptable professional engineer 
using principles of behavior modification" p.194. In this vein, Gerhard (1999) described a behavior modification approach to teaching engineering design.

Of considerable interest because of its K-12 implications, Carroll, (1997) described a project in which elementary school children were introduced to engineering through a bridge building exercise. Materials were prefabricated by engineering students, but the children engaged in the actual building. The project allowed possibilities for integrating the curriculum, with aspects of the bridge helping the teaching of geometry, reading, social studies, and physics.

Design in engineering classrooms has been the basis of empirical examination. Napper \& Hale (1999) reported on an assessment project aimed at determining the effectiveness of capstone design courses in selected engineering programs. The data were video-tapes of seniors presenting their prototypes and final designs. The projects were evaluated on a set of design criteria specified by ABET (Accreditation Board for Engineering and Technology). An important outcome of the project was increased awareness of the difficulties inherent in assessing student designs.

Koehn (1999) reported on a study aimed at determining how undergraduate and graduate students and practicing engineers from one university rated the importance of selected ABET criteria as aspects of the civil engineering curriculum. The criteria were (a) Engineering Codes and Standards, (b) Economic Factors, (c) Environmental Effects, (d) Sustainability, (e) Manufacturability (constructability), (f) Ethical Considerations, (g) Health and Safety Issues, (h) Social Ramifications, (i) Political Factors, and (j) Legal Issues. Two of the constraints, Environmental Codes and Standards, and Manufacturability (Constructability), were highly rated by both the students and practitioners. Rated low were Social Ramifications and Political Factors.

\section{Reflections on Engineering Design}

A first important lesson learned from looking at design within engineering and engineering education is that while it is central to the discipline, there is not consensus as to how it should be treated in the curriculum; and indeed, whether it should be included at all is still a matter of debate. One unsettled question is whether design is a rigorous enough area of engineering to warrant curriculum treatment. Where it is included, there is some disagreement as to whether it should be taught early or late in programs, or whether it should be infused across the curriculum.

However, there is general agreement on what constitutes design in engineering, how designing should proceed, and what role domain knowledge plays. There is also agreement that design is a fluid process which can be segmented into stages. Some of these stages, such as need identification, invention, and evaluation of alternative designs are well known to technology education. The distinction that French (1999) makes, though, between conceptual and analytic stages of design is extremely useful, showing the importance of contextual and engineering science knowledge, as well as inventiveness, in design decision making. More importantly, this division of 
design phases may suggest a way in which technology educators can delimit their work.

French (1999) wrote that the conceptual stage of design "is the phase where engineering science, practical knowledge, production knowledge, production methods, and commercial aspects need to be brought together, and where the most important decisions are taken" p.3. This way of conceiving of the stages of design appears to be approaching consensus proportions (e.g. Harris \& Jacobs, 1998; Middendorf \& Engelmann, 1998; Wild \& Bradley, 1998). As indicated above, Harris \& Jacobs (1995) reported that conceptual design and analytic design were key phases of their pedagogic approach when teaching a mechanical engineering design course. The object was to create an egg-carrying buggy powered by an internal combustion engine. The conceptual design phase focused on arriving at a suitable design. They wrote:

Immediately following the completion of the conceptual design, work commences on the analytic design to prove the functionality and endurance of the overall device and its components. Analytical designs typically commence with the establishment of overall speeds and loading, static and dynamic. These are translated into component loading, stresses and deflections. Depending on the component, thermodynamics and heat transfer analyses may be required in the determination of loading and stresses. The stresses are compared against the strength data for the initially selected component materials, and if necessary, alternate materials may be selected to meet yield and fatigue resistance. (p. 346)

Upon reflection, it would appear that conceptual design is within the normal purview of technology education. Analytic design poses a challenge. It is the point at which we arrive at a black box, when children construct the tallest tower, or design the fuel-efficient vehicle without understanding why. The question that arises is whether we would have done our part as a field if we delimited our role to conceptual design. One view emerging within technology education is that we could go further, into analytic design. Thus the underlying science and mathematics should be taught to students, to help them make predictions about their designs (e.g. Cotton, 2002; Roman, 2001). This line of thinking has its merits, and could be an area of much discussion, with implications for how the content knowledge of technology education teachers must be considered.

For clues to how we might think about this question we could reflect upon the debate of whether design should be taught to first-year engineering students. The question arises because in the first year, students would not yet have been grounded in the engineering sciences. Petroski's (1998) response to this is that it is possible for first-year engineering students to learn "the nature of design" through his paper-clip re-design problem. Students also have opportunity to learn first hand "the nature of engineering drawings, materials, manufacturability, economics, ergonomics, etc.” (p. 446). Some of his students even devised experiments to test their solutions. All get an opportunity to critique their own designs. Petroski's point is that even without an analytical 
design phase, his first year design course achieves significant learning objectives.

Pace's (1999) description of the use of product analysis as a means of teaching design is worth noting because the approach seems to be in keeping with established technology education traditions. Students take apart machines and tools routinely. Those same acts can now be the basis for their learning of engineering design, though they will come to the same limit as with conceptual design, when technical analysis is required.

\section{Conclusions and Implications}

Design in technology education corresponds in important ways with the design tradition of engineers. In both cultures, the open-ended problem in which the designer ventures from the known to the unknown is considered the prime challenge. Both come to the conceptual stage of design, where options are evaluated, taking into account design parameters. The engineering culture, more than the technology education culture, pays much attention to customer needs, to the question of trade-offs and constraints, to code requirements, to failure considerations, to manufacturability, and to the underlying science and mathematics. In practice, engineers rely on a memory bank of solution strategies that have worked in the past; they also call upon heuristics where quick estimations are needed.

The above examination of design from the perspective of the engineering profession, including insights from engineering education, provides the backdrop for ensuing comment on the challenges and opportunities for technology education as practitioners strive to come to terms with engineering. The comments are framed in terms of (a) what are the boundary limits of technology as it seeks to adopt engineering design as content? (b) how should content knowledge supportive of design be considered? (c) what should technology education teachers know to be able to teach design competently? and (d) what are the new possibilities for research?

\section{Boundary limits}

One challenge for technology education is how can it interpret engineering design authentically? This issue is settled with respect to conceptual design, which clearly has informed design teaching in schools. The issue of analytic design, however, remains open. How should the field deal with the limit of analytic design? One defensible option would be for technology education to accept this limit, and to view conceptual design as the extent of its domain, in much the way that Petroski (1998) approaches the teaching of design to first year engineering students. The focus is not on calculations, but on learning the essence of design, including critique of design, the role of trade-offs, teamwork, invention, etc. A second possible solution might be to approach analytic design in a limited way by including a set of completely worked out engineering design cases in the instructional repertoire of schools. A third option might be to adopt a collaborative approach to design, where technology teachers team with 
mathematics and science teachers, and with practicing engineers, in the teaching of design. This strategy would allow both analytic and conceptual aspects of design to be realized.

\section{Content Knowledge}

How much domain knowledge should technology students possess before it is assumed that they can competently tackle design problems? This question has to be given greater consideration now, because of links to engineering. Design in technology education often shows itself in the form of a space to be spanned by a bridge, a tall tower to be built, or a structure that will bear load. Students compete to see which individual or group has built the tallest tower, or has constructed the longest bridge, or has gotten its structure to bear the most weight. Often the teaching episode ends when a winner is identified, without students' gaining understanding of the reasons behind the success or failure of their attempts. That kind of rote approach to design misrepresents and grossly oversimplifies the task of the engineer, and perhaps more critically, it inhibits student creative performance, a critical aspect of which is the possession of requisite content knowledge (e.g. Lubart \& Sternberg, 1995).

Two scenarios that arise on the question of the importance of domain knowledge are (a) whether the intent is to teach just the generic process of design, or (b) whether it is to facilitate the solution of a design challenge within a particular domain. In the former case, it is conceivable that the teacher could proceed without consideration of domain knowledge. He/she could rely upon commonplaces (every-day materials or artifacts) about which the functional knowledge of students is assured, and could teach in a domain-independent manner. In the latter, students will need some degree of requisite preknowledge, depending upon the domain, whether electronics, materials, or construction. Since design in technology education could proceed along the two lines suggested above (content independent and content dependent) there is need in the discourse of the field to distinguish between them. Each approach has an important and peculiar purpose.

\section{Teacher Competence}

Just what should constitute the repertoire of technology education teachers if they are to teach design competently? Consistent with comments above with respect to student learning, the implications for teachers are that they would need at minimum to possess some measure of domain knowledge in the main disciplinary areas of the standards (such as manufacturing, construction or transportation). Teachers should also possess some agreed upon competence level in mathematics and science. There are implications here for the re-tooling of both pre-service and in-service teacher development programs. Moreover, teachers would need grounding in design practice, competence that they could acquire through industrial internships. 


\section{Research Possibilities}

Design offers many opportunities for inquiry in technology education, beginning with the challenges that attend its teaching and student learning. Such inquiry could span areas such as effective methods of assessment of student learning and effective teaching strategies. A more complete conception of the possibilities will emerge once the field works out an appropriate conceptual framework. Ultimately, such a framework can conceivably be informed by discourse streams such as multiple intelligences, learning styles, creativity, and cognition (e.g. Cropley, 1997; Houtz, 1994; Sternberg, 1990).

\section{Conclusion}

This article has considered the adjustments to be made within technology education for the field to come to terms with engineering as content. These adjustments have been shown to span not just curriculum and instruction but also inquiry and teacher preparation. Adjusting to the design imperative will be a more realizable proposition if technology educators seek to improve their competence by immersing themselves in environments where engineering design is practiced, and by actively collaborating with such practicing engineering designers. The higher the degree of collaboration that can be forged with practicing engineers, the more likely it will be that teachers will overcome initial tentativeness, and that they will teach design authentically. The result will be a greater chance that students will have authentic design experiences.

\section{References}

American Association for the Advancement of Science (1993). Benchmarks for scientific literacy. New York: Oxford University Press.

Bensen, M. J. \& Bensen, T. (1993). Gaining support for the study of technology. The Technology Teacher, 52(6), 3-5.

Carroll, D.R. (1997). Bridge engineering for the elementary grades. Journal of Engineering Education, 86(3), 221-226.

Cather, H., Morris, R., Philip, M. \& Rose, C (2001). Design engineering. Jordan Hill, Oxford: Butterworth-Heinemann.

Cotton, S.E. (2002). Making problem-solving simulations more realistic. The Technology Teacher, 62(3), 29-32.

Cropley, A.J. (1997). Fostering creativity in the classroom: General principles. In M. A. Runco (Ed.), The Creativity Research Handbook, Volume one (pp. 83-114), Norwood, NJ: Ablex Publishing Corporation.

Cross, N. (2000). Engineering Design Methods. Chichester, New York: John Wiley \& Sons.

Cross, N. (2002). Creative cognition in design: Processes of exceptional designers. In T. T. Hewitt \& T. Kavanaugh (Eds.), Creativity and Cognition,_(pp. 14-19), Loughborough University, UK: ACM Press.

Custer, R. L., Valesey, B. G., \& Burke, B. N. (2001). An assessment model for a design approach to technological problem solving. Journal of Technology Education, 12(2), 5-20. 
DeLuca, V.W. (1991). Implementing technology education problem-solving activities. Journal of Technology Education, 2(2), 5-15.

Denton, H.G. (1994). Simulating design in the world of industry and commerce: Observations from a series of case studies in the United Kingdom. Journal of Technology Education, 6(1). 16-31.

Dominick, P. G., Demel, J. T. Lawbaugh, W. M., Frueler, R. J., Kinzel, G. L., \& Fromm, E. L. (2001). Tools and Tactics of Design. New York. John Wiley $\&$ Sons.

Dym, C.L. (1994a). Engineering design: A synthesis of views. New Jersey: Cambridge University Press.

Dym, C.L. (1994b). Teaching design to freshmen: Style and content. Journal of Engineering Education, 83(4), 303-310.

Foster, P. N. \& Wright, M. D. (2001). How children think about design and technology: Two case studies. Journal of Industrial Teacher Education, $38(2), 40-64$.

French, M. (1992). Form, structure, and mechanism. New York: Macmillan Education.

French, M. (1999). Conceptual design for engineers. London: Springer.

Gerhard, G.C. (1999). Teaching design with behavior modification techniques in a pseudocorporate environment. IEEE Transactions on Education, 42(4), 255-260.

Getzels, J. W. (1982). The problem of the problem. In R. Hogarth (Ed). New directions for methodology of social and behavioral science; Question framing and response consistency (No. 11), (pp. ), San Francisco: Josseybass.

Getzels, J. W. \& Csikszenthmihalyi, M. (1976). The creative vision: A longitudinal study of problem finding in art. New York: Wiley.

Gustafson, B. J., Rowell, P. M., \& Guilbert, S. M (2000). Elementary children's awareness of strategies for testing structural strength: A three year study. Journal of Technology Education, 11(2), 5-22.

Harris, T. A. \& Jacobs, H. R. (1995). On effective methods to teach mechanical design. Journal of Engineering Design, (494), 343-349.

Hinrichs, T. R. (1992). Problem solving in open worlds: A case study in design. Hillsdale, NJ: L. Erlbaum Associates.

Houtz, J. C. ( 1994). Creative problem solving in the classroom: Contributions of four psychological approaches. In M. D. Runco (Ed) Problem finding, problem solving, and creativity, (pp.153-173). Norwood, New Jersey: Ablex Publishing Corporation.

Hubka, V. (1982) Principles of engineering design. (W.E. Eder, translator). London: Butterworth Scientific.

Institute of Electrical and Electronics Engineers. (2000). Technological literacy counts. Proceedings of a Workshop, Baltimore, Maryland, October 9-10, 1998. 
International Technology Education Association (2000). Standards for technological literacy - Content for the study of technology. Reston, Virginia: Author.

Johnson, J.R. (1989). Report of the Project 2061 Phase I Technology Panel. Washington D.C.: American Association for the Advancement of Science.

Johnson, S.D. (1988). Problem Solving Behavior Research Model for Industrial education. Journal of Industrial Education, 25(3), 29-40.

Johnson, S.D. (1989). A description of expert and novice performance differences on technical trouble-shooting tasks. Journal of Industrial Teacher Education, 26(3), 19-37.

Johnson, S.D. \& Chung, S-P. (1999). The effect of thinking aloud pair problem solving (TAPPS) on the troubleshooting ability of aviation technician students. Journal of Industrial Teacher Education, 37(1), 7-25.

Koch, J. \& Burghardt, M. D. (2002). Design technology in the elementary school: A study of teacher action research. Journal of Technology Education, 13(2), 21-32.

Koehn, E. (1999). Preparing students for engineering design and practice. Journal of Engineering Education, 88(2), 163-167.

Koen, B. V. (1985). Definition of the engineering method. Washington, DC: American Society for Engineering Education.

Koen, B. V. (1994). Toward a strategy for teaching engineering design. Journal of Engineering Education, 83(3), 193-201.

Koestler, A. (1969). The act of creation. London: Hutchinson.

Lewis, T., Petrina, S., \& Hill, A. M. (1997). Problem-posing-Adding a creative increment to technological problem solving. Journal of Industrial Education, 36(1), 5-35.

Lubart, T. I. \& Sternberg, R. J. (1995). An investment approach to creativity: theory and data. In S. M. Smith, T. B. Ward and R. A. Finke (Eds). The Creative Cognition Approach (pp. 271-302). San Diego: Academic Press, 271-302

McCauley, M.H (1990). The MBTI and individual pathways in engineering design. Journal of Engineering Education, 80(5), 537-542.

McMasters, J. H. \& Ford, S. D. (1990). An industry view of enhancing design. Journal of Engineering Education, 80(5), 526-529.

Mertz, R.L. (1997). A capstone design course. IEEE Transactions on Education, 40(1), 41-45.

Middendorf, W. H. \& Engelmann, R. H. (1998). Design of devices and systems. New York: Marcel Dekker, Inc.

Mullins, C. A., Atman, C. J., \& Shuman, L. J . (1999). Freshman engineers' performance when solving design problems. IEEE Transactions on Education, 42(4), 281-287.

Mumford, M. D. Reiter-Palmon, R., \& Redmond, M. R. (1994). Problem construction and cognition: Applying problem representations in ill-defined domains. In M.A. Runco (Ed), Problem finding, problem solving, and creativity, (pp. 3-39). Norwood, NJ: Ablex. 
Napper, S. A. \& Hale, P. N. (1999). Using design projects for program assessment. Engineering Education, 88(2), 169-172.

Neumann, K.E. (2003). The importance of redesign. The Technology Teacher, 63(3), 7-9.

Pace, S. (1999). Teaching mechanical design principles on engineering foundations. International Journal of Mechanical Engineering Education, 28(1), 1-13.

Pahl, G. \& Beitz, W. (1996). Engineering design. New York: Springer.

Parkinson, E. (2001). Teacher knowledge and understanding of design and technology for children in 3-11 age group: A study focusing on aspects of structures. Journal of Technology Education, 13(1), 44-58.

Pearson, G. \& Young, A. T. (2002). Technically speaking: Why all Americans need to know about technology. Washington DC: National Academy Press.

Peterson, C. R. (1990). The desegregation of design. Journal of Engineering Education, 80(5), 530-532.

Petroski, H. (1996). Invention by design. Cambridge, Massachusetts: Harvard University Press.

Petroski, H. (1998). Polishing the Gem: A first-year design project. Journal of Engineering Education, 87(4), 445-449.

Roman, H. T. (2001). Technology education-Process or content? The Technology Teacher, 60(6), 31-33.

Savage, E. \& Sterry, L. (1990). A conceptual framework for technology education. The Technology Teacher, 50(1), 6-11.

Sternberg, R. J. (1990). Thinking styles: Keys to understanding student performance. Phi Delta Kappan, 71(5), 366-371.

Wertheimer, M. (1968). Productive thinking. Northampton, UK: Tavistock Publications.

West, H., Flowers, W., \& Gilmore, D. (1990). Hands-on design in engineering education: Learning by doing what? Journal of Engineering Education, 80(50). 560-564.

Westberry, R. (2003). Selecting instructional strategies for technology education. Fifty - second yearbook of the Council of Technology Teacher Education. New York: McGraw-Hill, 101-115.

Wild, P. M. \& Bradley, C. (1998). Employing the concurrent design philosophy in developing an engineering design science program. International Journal of Mechanical Engineering Education, 26(1), 51-64.

Zubrowski, B. (2002). Integrating science into design technology projects: Using a standard model in the design process. Journal of Teacher Education, 13(2), 47-70. 